\title{
Language Attrition Study Implications on College Foreign Language Learning
}

\author{
Dan Li \\ Foreign Language Education Institute, Beihua University of Jilin 132000 \\ bettylidan@qq.com
}

Keywords: Language attrition; Implication; College; Foreign language

\begin{abstract}
Through the study of language attrition, the paper analyzed the factors of language attrition of foreign language and elaborated language attrition Study Implications on college foreign language learning. Language attrition refers to second or foreign language learning in language teaching after receiving a second or foreign language level generated through several time degradation phenomena. As the impacts of other factors such as learning time, learning content and learning methods, this phenomenon in college English learning is particularly evident. Therefore, the study of language attrition has significance for foreign language learning. This paper mainly discusses the theory of language attrition research and the implications as well as some suggestions and opinions for college foreign language learning.
\end{abstract}

\section{Introduction}

Not only have strong language acquisition abilities, human beings also have strong abilities to make oblivion and loss of language. This incapacity in linguistics is called language attrition (LA: Language attrition). The so-called language attrition refers to bilingual or multilingual users used to reduce or stop their ability to use the language with the passage of time gradually decreased [1]. As though China attaches great importance to teaching English, but for our English learners English is only one foreign language only which is not the whole society common locale. Most English learners in real life have only little contact with English and there is no opportunity to practice which leads to the attrition of English. Therefore, the study of LA has an important role in guiding both language learning and teaching.

\section{Study on Current Situation of Language Attrition}

Studies on Language Attrition Research Categories. Language attrition research involves a number of fields, such as psychology, neurology, sociology, linguistics. Objects of study are also diverse, in the case of pathological or non-pathological language attrition language attrition, abrasion mother tongue environment or the environment under the second language, children or adult language attrition and so on. This paper does not include abrasive "pathological type" language attrition. This type of natural language attrition by Van Els (1986) is divided into four categories.

The first category refers to the mother tongue mother attrition environment, such as the elderly lose language, dialect death and loss of language dialect groups.

The second category refers to the second locale attrition of mother tongue. Such as native language skills attrition by immigration phenomenon is in this category. For example, a person moved to England as a child, he will probably only speak English and do not speak the Chinese language after a few years.

The third category refers to attrition environment up a second or foreign language environment, which means the second or foreign language learners after receiving no language teaching due to prolonged use of the generated second or foreign language skills, loss or degradation phenomena. As the majority of our foreign language learners will produce the phenomenon of language attrition after the class. 
The fourth category refers to the second locale attrition environment of second language or foreign language, such as the elderly immigrant second language attrition. For example, some Chinese people learned English in Chinese environment and moved to the Chinese American community working for some time after the English attrition.

Table 1 Categories of Language Attrition by Van Els

\begin{tabular}{|c|r|c|}
\hline Language & Mother Language & Second Language \\
\hline \multirow{2}{*}{ Environment } & Type 1 & Type 3 \\
\cline { 2 - 3 } & Type 2 & Type 4 \\
\hline
\end{tabular}

Wherein the third category which is in the mother language environment, the second or foreign language attrition deserves our attention because it is closely related to the stage of our Chinese language teaching environment. In China, English is only a foreign language which does not have a common language environment. Since the majority of English learners in real life have little contact with the language and lack of opportunity to practice therefore the attrition occurs under the Chinese environment.

Factors Affecting Foreign Language Attrition. Critical Thresholds, the proficiency level of foreign before foreign language attrition is a key factor. The study found that the proficiency level of language learners before attrition not only makes inversion phenomenon but also makes various effects by different levels of intensity of foreign, where there is a clear dividing line. In general, the higher proficiency foreign language level the learners have, the more time they keep the language better because their language level is not easy to lose. The lower level of foreign language learners, the easier they get the attrition. Learners in the upper or lower boundaries vary a lot. Language attrition rate and its existence have amount of difference, the dividing line is known as the "critical threshold". For the language learners who once crossed the "critical thresholds", their foreign language proficiency level will be relatively stable.

Social Learning Environment is the second one. Foreign language learning in our society as a whole does not belong to a common locale which means the language is not actually used. Foreign language learners typically do not get acquisition of foreign language in the classroom environment while in extracurricular they get the language input nor do they have the opportunity to practice the language let alone to apply their knowledge. Since there is no chance the University in extracurricular language acquisition, so some college students won't go to practice English language after the courses. They significantly reduce exposure to English, which means if they do not keep the language learning intentionally, their language learning will be significant attrition.

Learning Motivation is the third one. Learning motivation is the desire and the driving force of language learners. Different learners have different motivation. Motivation can be divided into comprehensive learning motivation and instrumental motivation. Comprehensive learner motivation is to melt into the population, which reflects the learner's personal interest of target people and culture. Learner has comprehensive motivated enthusiastic about aliens, learn about their culture. This kind of motivation is relatively strong and durable, so they can get more language input. The instrumental motivation refers to practical purposes. It reflects the actual value of the foreign language and advantageous. The existence of such motives undoubtedly has a role in promoting the language. This kind of learners considers learning the necessary content. Moreover, once they achieve the purpose of language, their learning stops. In China, the vast majority of students who have instrumental motivation to learn English learn a foreign language for a job, promotion or through examinations. Once they reach the end, they never look for opportunities to practice the language. This will naturally lead to rapid erosion of English.

Attrition time is the fourth one. Time is affected by erosion is one of College English abrasion. After completion of formal education in English, if English is used to reduce or stop language attrition occurs. Its English abrasion process presents a 'fast before a slower one after fast "development trend. That stop using English pre abrasion is very serious. Mid-obvious or non-abrasive. Late erosion and accelerated. 
Time is also a factor for Students' language attrition. At the end of formal language education, if the language is reduced or stopped, language attrition occurs. Its language attrition process presents a "fast at beginning - Slow in the middle - fast at the end" trend. It means when language learners stop the use of foreign the serious attrition begins. In the mid-period it is unobvious or non-attrition and at the end it accelerates.

\section{Implications for Foreign Language Learning}

Because of the above factors which affect College Students attrition in our Chinese environment, the state, schools, teachers and students themselves should make joint efforts to create a good environment for learning foreign language, improve teaching methods and mode of college English and correct the attitude towards learning in order to overcome the language attrition and improve the efficiency of learning foreign language.

Grading the Level of Foreign Language in University. When the level of foreign language learners reach a certain level, this level will be relatively stable. Reducing the impact of the passage of time and the opportunity to use the language is also reduced, thereby reducing the attrition. Cognitive Pragmatic astrologer that what the language learners get is a procedural knowledge. Such knowledge is acquired and consolidated in a certain period which can last a lifetime. In order to prevent attrition of the second language effectively, the basic target level of second language learning should be increased by one level in the existing standard. Based on this understanding, the state may make the current requirements of CET exam to a higher level. China also can develop our own standards according to foreign standards which are suitable for China's situation. These standards can be set as the ultimate level of English language learning requirements. This will be instructive for China's English teaching.

Improve the Learning Environment. Maintain continuing education of college students and engage them in active practice of foreign language words to avoid the attrition caused by the environment obstacles. Since in our Chinese language environment, Students are lack of opportunities to practice and the input of the language, so the language skills tend to be quickly lost or degraded. Therefore, it is an important method to apply their knowledge to overcome language loss for the college students. Schools could try to open a number of language courses which all students can participate in a continuing education, which could help college students keep in their foreign language and decrease the reduction caused by attrition in English. Guide and encourage the learner actively looking for opportunities to practice, such as reading foreign newspapers and magazines, watching Western movies and other opportunities to increase changes of practicing foreign language.

Reform of College English Teaching. Language teaching has long been a traditional way of classroom teaching which is not conducive to mobilize the learning enthusiasm and students' Language practical application. The model should favor the direction of individualized study and independent study, reflect the principles of practicality combining fun and culture and be able to fully mobilize the initiative of students by making the practical ability in the first place. While college Language teachers should arrangement of teaching content reasonably, pay attention to language proficiency and strengthen cultural understanding of the language so as to avoid attrition English effectively.

Correct Attitude towards Learning. Good motivation could inhabit the language attrition. Therefore, students should establish a correct attitude towards learning foreign language; develop interest in learning in order to make active learning and strength exercises which could avoid language attrition. From this point, teachers should help students clarify their learning objectives, strive to maintain the students' self-image and encourage students to experience success in order to strengthen the motivation to learn the foreign language. So students can develop motivation to learn, which could avoid "dumb Language Learning." According to "critical threshold period" theory, only through a large number of foreign language proficiency input, which help language learners to strengthen, consolidate, could they eventually cross the "critical threshold period" and 
reduce the loss to a minimum. Therefore, college English teachers should provide students with a large number of inputs which is suitable for the actual level of language in order to allow students to perceive the language learning rules.

Continuing Education. We will not only improve language skills, but should emphasize keeping and maintenance of foreign language skills. Otherwise, previous efforts will disappear. This requires the learners keep the language skills through continuing education. How to effectively maintain the level of foreign language of the language learners and help them to prevent language attrition worth pondering is important. In the United States, in order to prevent the attrition in military, Languages Project Department of the Army clearly stipulates, for certain foreign language test must re-test once every two years. In China, foreign language exam titles apart long service life and can not make up for the attrition of language skills.

\section{Summary}

Thus, the learner must take active and effective measures to try and reach across the "critical threshold" in order to minimize the extent of language attrition degree at the end of the formal education based on their own situation. Improve the teaching environment, diversify the teaching methods and change the language learner's own cognitive are needed to make the appropriate improvements, which will make language attrition minimized. How to maintain the required level of foreign language and reduce the language attrition are indeed the worthy fields of in-depth study of foreign language education issues.

\section{References}

[1] H. Seliger: Deterioration and Creativity in Childhood Bilingualism (2009).

[2] P. Herdina and U. Jessner: A Dynamic Model of Multi-lingualism: Perspectives of Change in Psycholingnistics (2002).

[3] T.O. Nelson: Detecting Small Amounts of Information in Memory: Savings for Nonrecognized Items ,Vol.5(2008), p.221.

[4] P. Ecke: Language Attrition and Theories of Forgetting: A Cross-Disciplinary Review, Vol.3,2004.

[5] G. Hayashi: Language Attrition of Japanese Returnee Students, Vol.1(2011),No.3, p.4.

[6] E. Bylund, N. abrahamsson and K. Hyltenstam: The Role of Language Aptitude in First Language Attrition: The Case of Pre-pubescent Attiters.Vol.3(2010)No.5, p.31.

[7] M.S. Schmid and Keijzer, M: First Language Attrition and Reversion among Older Migrants. Vol.5(2009), p200.

[8] M.S. Schmid: Defining Language Attrition.Vol.2(2008)No.2, p.138.

[9] Kpke, B: Language Attrition at the Crossroads of Brain, Mind, and Society (2007).

[10]Palliser, C: Critical Periods in Language Acquisition and Language Attrition (2007).

[11] Sands miller and A. Lbrugman: The Lexicon in Language Attrition: The Case of Nuu(2007).

[12] A. Pavlenko: Emotions and Multilingualism (2005).

[13]B. Kpke and M.S. Schmid: Language Attrition: The Next Phase( 2004).

[14] Meara P. Modeling Vocabulary Loss. Vol 2(2004), p.25.

[15]M. Ben-Rafael and M.S. Schmid: Language Attrition and Ideology: Two Groups of Immigrants in Israel(2007). 